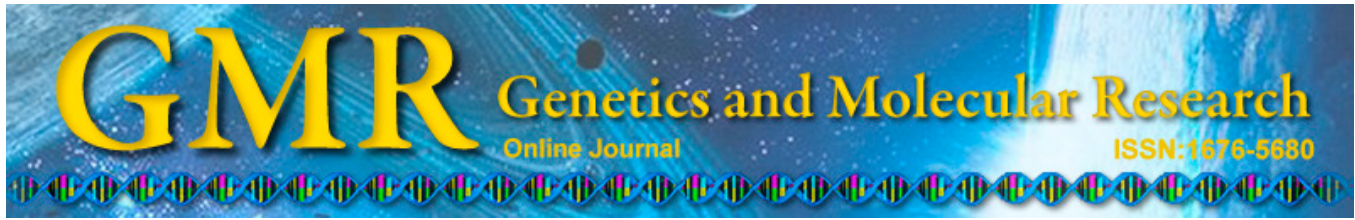

\title{
Effect of low temperatures on BAX and BCL2 proteins in rats with spinal cord ischemia reperfusion injury
}

\author{
P. Zhu' ${ }^{1 *}$ M.Y. Zhao ${ }^{1,2 *}$, X.H. Li ${ }^{1 *}$, Q. Fu ${ }^{1}$, Z.F. Zhou ${ }^{1}$, C.F. Huang ${ }^{1}$, \\ X.S. Zhang ${ }^{1}$, H.L. Huang ${ }^{1}$, Y. Tan ${ }^{3}$, J.X. Li ${ }^{1}$, J.N. Li ${ }^{1}$, S. Huang ${ }^{1}$, \\ M. Ashraf ${ }^{3}$, C. Lu ${ }^{1}$, J.M. Chen ${ }^{1}$, J. Zhuang ${ }^{1}$ and H.M. Guo ${ }^{1}$ \\ ${ }^{1}$ Department of Cardiovascular Surgery, Guangdong General Hospital, \\ Guangdong Cardiovascular Institute, Guangdong Academy of Medical Sciences, \\ Guangzhou, China \\ ${ }^{2}$ Department of Pediatrics, The Third Xiangya Hospital, \\ Central South University, Changsha, China \\ ${ }^{3}$ Department of Pharmacology, UIC College of Medicine, Chicago, IL, USA \\ *These authors contributed equally to this study. \\ Corresponding authors: J.M. Chen / J. Zhuang / H.M. Guo \\ E-mail: chenjimei_1@163.com / zhuangjian_1@163.com / guohuiming@vip.tom.com
}

Genet. Mol. Res. 14 (3): 10490-10499 (2015)

Received December 18, 2014

Accepted May 18, 2015

Published September 8, 2015

DOI http://dx.doi.org/10.4238/2015.September.8.10

\begin{abstract}
We evaluated changes in BAX and BCL2 expression levels after spinal cord ischemia/reperfusion injury (SCII) and hypothermia during operations in rats. Eighty rats were divided into four groups: Group A $\left(\mathrm{N}=20,18^{\circ} \mathrm{C}\right)$; Group $\mathrm{B}\left(\mathrm{N}=20,28^{\circ} \mathrm{C}\right)$; Group $\mathrm{C}(\mathrm{N}=20$, room temperature); and Group $\mathrm{D}(\mathrm{N}=20$, sham operation control). Spinal cord ischemia was induced for $90 \mathrm{~min}$. Hypothermia was induced $15 \mathrm{~min}$ before, and maintained during ischemia, followed by heating to normothermia for $30 \mathrm{~min}$ after reperfusion. Motor function of the lower limbs was evaluated according to the Tarlov score at 72 and $168 \mathrm{~h}$. For each rat, spinal cord samples were taken at 6, 24, $72 \mathrm{~h}$, and $1 \mathrm{week}$ to evaluate the histopathological changes, neuronal
\end{abstract}


apoptosis, and BAX and BCL2 expression levels. Compared with normothermia, hypothermia significantly improved hind limb function; Group B achieved a higher score than Group A. Group D showed no neurologic deficiency, while the other groups showed various degrees. Group C exhibited greater neuronal apoptosis, higher BAX expression, but lower BCL2 expression than the other groups. Compared with Group A, BAX was expressed less and BCL2 more in Group B, and there was less apoptosis in Group B. Hypothermia preserves hind limb motor function and reduces neuronal death, thereby protecting rats from SCII. The spinal cord may be protected from SCII by inhibition of BAX and activation of BCL2. However, deep hypothermia may inhibit the expression of BCL2, resulting in a worse outcome than mild hypothermia.

Key words: Hypothermia; Spinal cord ischemia/reperfusion injury; BAX; BCL2

\section{INTRODUCTION}

Surgery on the chest often requires blocking of the abdominal aorta. However, the associated spinal cord ischemia/reperfusion injury (SCII) can cause paraplegia in severe cases (Guo et al., 2004). Conducting heart operations at low temperatures as a means of protecting the central nervous system has been widely used in clinics, and the mechanisms by which SCII is protected against, such as inhibition of apoptosis, excitatory amino acid toxicity, and inflammatory reactions, have been reported (Mahura, 2003). However, these mechanisms are still not completely clear. The protective effects against SCII at various low temperatures (moderately low temperatures and very low temperatures) have rarely been reported in China. Güler et al. (2010) established the rat spinal cord ischemia/reperfusion model using the two-clip method, and reported the influence of low temperature on the apoptosis of cerebral neuronal cells in that model during the acute and subacute stages. Here, we report our preliminary investigation of the neuroprotective effect of different temperatures on the rat spinal SCII model. Our objective was to determine whether the protective effect is closely related to the inhibition of apoptosis in nerve cells to improve the SCII protection method.

\section{MATERIAL AND METHODS}

\section{Establishment of animal SCII model and grouping}

Eighty adult male Sprague Dawley rats (weight $200 \pm 20$ g) were provided by the Guangdong Province Medical Animal Experimental Center. They were randomly divided into four groups with 20 rats in each group. The indices of five rats from each group were separately measured at three different points: $24,72 \mathrm{~h}$, and 1 week.

Rats in the $18^{\circ} \mathrm{C}$ low-temperature treatment group (Group A) were anesthetized by intraperitoneal injection of $10 \%$ chloral hydrate $(300 \mathrm{mg} / \mathrm{kg})$. A longitudinal incision was made in the abdominal wall along the ventral midline, and the proximal abdominal aorta was exposed along the left renal artery bifurcation. The distal abdominal aorta was separated and 
exposed at the bifurcation of the iliac artery. An artery clamp was applied to the distal end of the near abdominal aorta. The temperature of the rats was reduced to approximately $8^{\circ} \mathrm{C} 20$ min before clamping, and a systemic low temperature of $18^{\circ} \mathrm{C}$ was maintained during clamping. The artery clamp was opened after $90 \mathrm{~min}$.

For the rats in the $28^{\circ} \mathrm{C}$ low-temperature treatment group (Group B), the procedure was the same as for the Group A, except that the rats' body temperature was reduced to $28^{\circ} \mathrm{C}$ and maintained at that temperature for the clamping period. By gently reheating after lifting the clamp, the rats' temperature was increased to normal within $0.5 \mathrm{~h}$.

For the normal operation control group (Group C), the surgical procedure was the same as in the previous experiments except that it was conducted at room temperature and there was no cooling before clamping. In the normal temperature sham operation group (Group D), anesthesia, laparotomy, and separation of the abdominal aorta took place at room temperature, but there was no clamping, and the abdominal cavity was closed after $90 \mathrm{~min}$.

\section{Neural function score}

The nerve function scores for rat lower limbs were assigned according to standard Tarlov scores (Rivlin and Tator, 1977) (Grade 0: no detectable hind limb activity; Grade 1: weak detectable hind limb activity; Grade 2: the subject's hind legs moved against gravity but the subject was unable to stand; Grade 3 : the subject could stand but could not jump; Grade 4: the function of the hind limb was fully restored and the subject jumped normally). We scored the neurological behavior. The functional recovery rate of the hind $\operatorname{limb}=$ (the average score of the low-temperature protection group - the average score of the experimental control group at normal temperature) / the average score of the of lowtemperature protection group $\mathrm{x} 100 \%$.

\section{Hematoxylin and eosin (HE) staining and Nissl staining}

Five rats from each group were randomly taken at $24 \mathrm{~h}$ and 1 week after reperfusion to expose the spinal cord and extract lumbosacral spinal cord samples. The samples were embedded in paraffin and conventional pathological sections were produced, which were subjected to HE and Nissl staining (toluidine blue staining). To observe the morphological changes of spinal cord tissue under the light microscope, the samples were divided into three levels in accordance with the pathological grading standards: level I: normal spinal cord or a small amount of denatured granular tissue and vacuolar degeneration in the cytoplasm; level II: moderate hyperchromatic and normal neuron cell interphase; and level III: a large degree of neuronal necrosis and dissolution.

\section{Immunohistochemical coloration}

The paraffin sections were immersed in $3 \% \mathrm{H}_{2} \mathrm{O}_{2}$ at room temperature for $90 \mathrm{~s}$, blocked with normal animal serum for $20 \mathrm{~min}$, and BAX or BCL2 were incubated with 1:200 rabbit anti-rat (Abcam) overnight at $4^{\circ} \mathrm{C}$ and biotin-labeled goat anti-rabbit IgG at $37^{\circ} \mathrm{C}$ for $2 \mathrm{~h}$. The streptomycin-avidin-biotin peroxidase complex was added at $37^{\circ} \mathrm{C}$ for $1 \mathrm{~h}$, followed by washing three times with $0.01 \mathrm{M}$ PBS for 5 min each time before changing the fluid; 3,3'-diaminobenzidine (DAB) and nickel sulfate colorant were used for dehydration and mounting. Positive cells were purple/blue. 


\section{In situ detection of cell apoptosis using terminal deoxynucleotidyl transferase dUTP nick-end labeling (TUNEL)}

Frozen sections was digested with proteinase $\mathrm{K}$ for 60 min, using $50 \mu \mathrm{L} 3 \% \mathrm{H}_{2} \mathrm{O}_{2}$ methanol solution to block endogenous peroxidase at room temperature for $10 \mathrm{~min}$. The sections were immersed in a 11\% Triton-100 ice bath for $5 \mathrm{~min}$. The TUNEL reaction liquid (50 $\mu \mathrm{L}$ ) was incubated at $37^{\circ} \mathrm{C}$ for $60 \mathrm{~min} ; 50 \mu \mathrm{L}$ peroxidase was washed with PBS three times for 5 min each time before changing the fluid. DAB and nickel sulfate colorant were used for dehydration and mounting. The apoptotic nerve cell nuclei were granular and colored shades of purple/red.

\section{Western blot}

The animals were anesthetized at the appropriate times and the spinal cord was quickly extracted. Lysate (Pik Wan Days Biotechnology Co. Ltd.) was used to extract proteins and the protein concentration was measured by the Bradford method, ensuring consistency by taking the same amount of protein $(30 \mu \mathrm{g})$ for the samples. Sodium dodecyl sulfate polyacrylamide gel electrophoresis was used to isolate the proteins, and the protein bands were transferred to nitrocellulose membrane. The proteins were blocked with $50 \mathrm{~g} / \mathrm{L}$ skimmed milk for $3 \mathrm{~h}$, and 1:200 rabbit anti-rat antibody was added to BAX or BCL2 for incubation at $37^{\circ} \mathrm{C}$ overnight, followed by 1:200 horseradish peroxidase-labeled goat anti-rabbit IgG at $37^{\circ} \mathrm{C}$ for $2 \mathrm{~h}$. The samples were colored with $\mathrm{DAB}$ and nickel sulfate. The integral absorbance of the western blot strip was measured and analyzed using the Gel-Pro 32 software and the WO-9413B gel imaging system, and the relative expression levels were calculated according to the ratio of integral absorbance in each sample strip and the $\beta$-actin reference strip.

\section{Statistical analysis}

All data were analyzed with the SPSS13.0 statistical software and the pathological cumulative scores were analyzed by the rank sum test. The data between pairs of groups were compared by the independent $t$-test, and $\mathrm{P}<0.05$ was considered to be statistically significant.

\section{RESULTS}

\section{Neurological function scores of rat hind limbs}

The Tarlov scores for rat hind limbs in the four groups $72 \mathrm{~h}$ and 1 week after operation are shown in Table 1. The nerve function of animals in the sham operation group was normal. When compared with the sham operation group, the function of the hind limbs in the experimental control group at normal temperatures was significantly reduced $(\mathrm{P}<0.01)$, and there was also a significant difference $168 \mathrm{~h}$ after operation $(\mathrm{P}<0.01)$. When compared with the experimental control group at normal temperatures, the low-temperature protection group obviously recovered after $72 \mathrm{~h}(\mathrm{P}<0.01)$, and there was a significant difference after $168 \mathrm{~h}$. Analysis of variance between groups at low temperature showed that the low-temperature $28^{\circ} \mathrm{C}$ protection group (Group $\mathrm{B})$ recovered more than the low-temperature $18^{\circ} \mathrm{C}$ protection group (Group $\left.\mathrm{A}\right)(\mathrm{P}<0.01)$, and there were no significant differences in the scores at 72 and $168 \mathrm{~h}(\mathrm{P}>0.05$; see Table 1$)$. 
Table 1. Tarlov function scores for rat hindlimbs in each group $72 \mathrm{~h}$ and 1 week after operation (means $\pm \mathrm{SD}, \mathrm{N}=5$ ).

\begin{tabular}{|c|c|c|c|c|c|c|c|c|c|}
\hline & Group D & Group C & Group A & Group B & $\begin{array}{l}\text { Function recovery } \\
\text { rate }^{\mathrm{a}}\end{array}$ & $\begin{array}{l}\text { Function recovery } \\
\text { rate }^{b}\end{array}$ & $\mathrm{P} 1$ & $\mathrm{P} 2$ & P3 \\
\hline & $4.00 \pm 0$ & $2.21 \pm 0.52$ & $2.86 \pm 0.55$ & $3.07 \pm 0.49$ & $23.25 \%$ & $28.26 \%$ & $\mathrm{P}<0.01$ & $\mathrm{P}<0.01$ & $\mathrm{P}<0.01$ \\
\hline 1 week & $4.00 \pm 0$ & $2.33 \pm 0.48$ & $2.93 \pm 0.45$ & $3.27 \pm 0.39$ & $25.71 \%$ & $28.57 \%$ & $\mathrm{P}<0.01$ & $\mathrm{P}<0.01$ & $\mathrm{P}<0.01$ \\
\hline
\end{tabular}

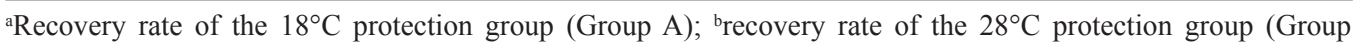
B). $\mathrm{P} 1<0.01$ when the experimental groups were compared with the sham operation group. $\mathrm{P} 2<0.01$ when the experimental groups were compared with the normal temperature operation group. P $<0.01$ when the two experimental groups were compared.

\section{Results of HE staining and Nissl staining}

A light microscope revealed that in the sham operation group (Group D) at each time point the nerve cell body was full, the nucleus was complete, the connective tissue around the neurons was arranged neatly, and there were no cell edema or white "halo" gaps. In Groups A, $\mathrm{B}$, and $\mathrm{C}$ at the different time points there were varying degrees of edema, the volume of some neurons was reduced, the nuclei appeared shrunken, and a white "halo gap" and vacuolation surrounded the nerve cells. The proliferation of endothelial cells around the blood vessels was visible. The changes were most obvious at $72 \mathrm{~h}$. The pathology scores of 15 rats in Group D were grade I; the pathology scores of seven and eight rats in Group C were grade II and grade III, respectively; the pathology scores of five, eight, and two rats in Group A were grade I, grade II, and grade III, respectively; and the pathology scores of six and nine rats in Group B were grade I and grade II, respectively. The pathological cumulative scores were subjected to analysis of variance, and the result was most obvious in Group $\mathrm{C}$ when comparisons were made within the group, followed by Groups A and B $(\mathrm{P}<0.05)$.

The results of Nissl staining revealed normal distribution of Nissl bodies in neurons at each time point in Group D, and the cell body had a full shape and a clear boundary; Groups $\mathrm{A}, \mathrm{B}$, and $\mathrm{C}$ showed varying degrees of volume decrease in the neurons at each time point. The Nissl bodies decreased and there was karyopyknosis deep dyeing, most obviously at 72 $\mathrm{h}$ in Group $\mathrm{C}$ when comparisons were made within the group; in Groups $\mathrm{A}$ and $\mathrm{B}$, there was a small volume reduction in neurons (Figure 1A-D and Figure 2A-D).

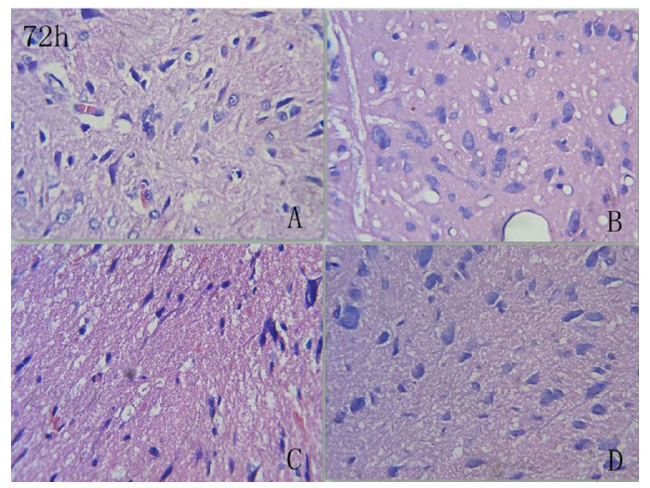

Figure 1. Hematoxylin and eosin staining after reperfusion for $72 \mathrm{~h}(10 \mathrm{x} 10)$. A. Low-temperature $\left(18^{\circ} \mathrm{C}\right)$ protection group; B. low-temperature $\left(28^{\circ} \mathrm{C}\right)$ protection group; C. normal temperature operation control group; D. sham operation group. 


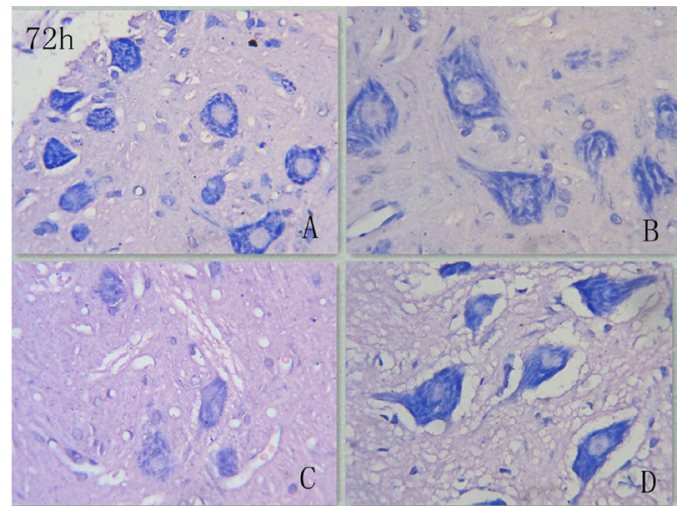

Figure 2. Nissl staining after reperfusion for $72 \mathrm{~h}(40 \mathrm{x} 10)$. A. Low-temperature $\left(18^{\circ} \mathrm{C}\right)$ protection group; B. lowtemperature $\left(28^{\circ} \mathrm{C}\right)$ protection group; C. normal temperature operation control group; D. sham operation group.

\section{Results of TUNEL staining}

Group D showed a small number of TUNEL-positive cells. There was a large number of TUNEL-positive cells in Group C, and the nuclei were stained deep brown. TUNELpositive cells were detected in Groups A and B, but there were significantly less than in Group C; Group A had more obvious staining than Group B. The number of TUNEL-positive cells significantly increased after $24 \mathrm{~h}$, a relative maximum mainly appeared after reperfusion at $72 \mathrm{~h}$, and the positive cells obviously declined in number 1 week after injury (Figure 3A-D).

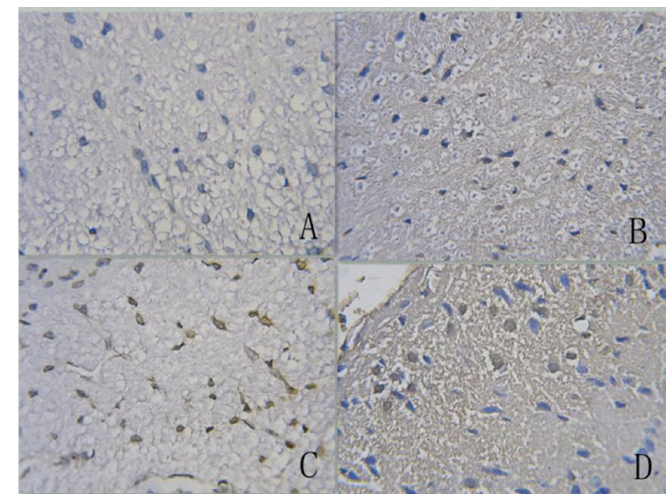

Figure 3. Terminal deoxynucleotidyl transferase dUTP nick-end labeling (TUNEL) staining (10 x 10). A. Lowtemperature $\left(18^{\circ} \mathrm{C}\right)$ protection group; B. low-temperature $\left(28^{\circ} \mathrm{C}\right)$ protection group; $\mathbf{C}$. normal temperature operation control group; D. sham operation group.

\section{Results of immunohistochemistry}

There were different levels of expression of BAX protein in each group: expression in Group $C$ was significantly higher than in the other groups, and was slightly more noticeable in Group A than in Group B. The expression of BCL2 protein was strongest in Group D, followed by Group B, Group A, and Group C (Figure 4A-D and Figure 5A-D). 


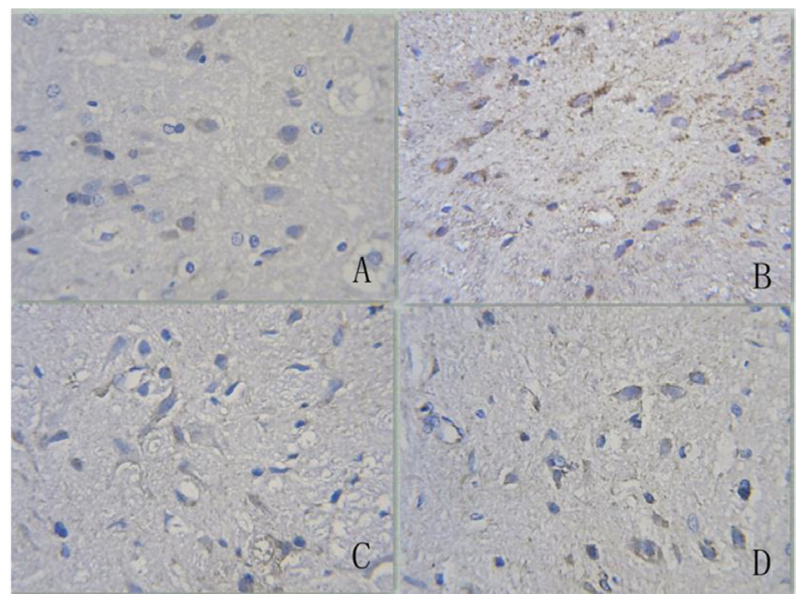

Figure 4. BAX protein immunohistochemical results $(10 \times 10)$. A. Low-temperature $\left(18^{\circ} \mathrm{C}\right)$ protection group; $\mathbf{B}$. low-temperature $\left(28^{\circ} \mathrm{C}\right)$ protection group; $\mathbf{C}$. normal temperature operation control group; $\mathbf{D}$. sham operation group.

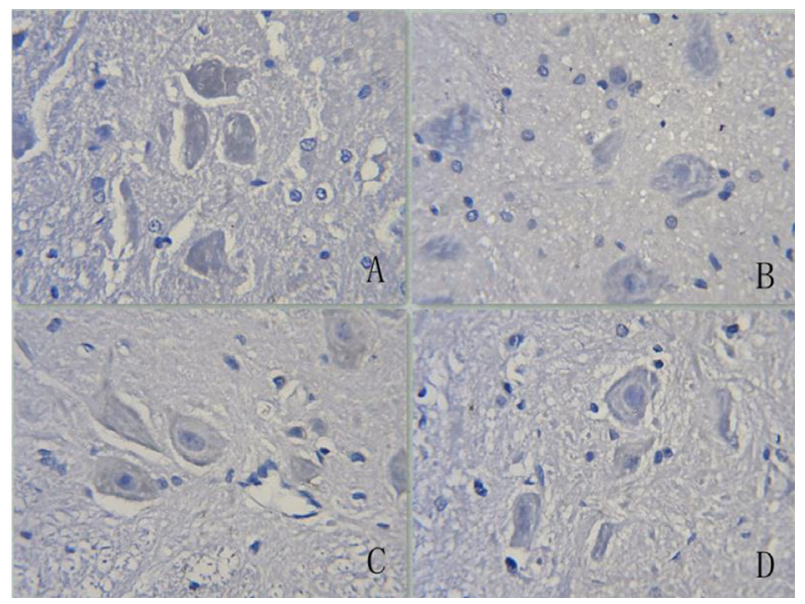

Figure 5. BCL2 protein immunohistochemical results $(10 \times 10)$. A. Low-temperature $\left(18^{\circ} \mathrm{C}\right)$ protection group; $\mathbf{B}$. low-temperature $\left(28^{\circ} \mathrm{C}\right)$ protection group; $\mathbf{C}$. normal temperature operation control group; $\mathbf{D}$. sham operation group.

\section{Results of western blot analysis}

The results of western blot analysis for each specific protein in each group at three time points using the Gel-Pro 32 software and the WO-9413B gel imaging system to analyze the protein bands can be seen in Figure 6. The integral optical density ratios are shown in Table 2. The results indicate that the expression of BAX in Group $\mathrm{C}$ was significantly higher than in the other groups at three time points by analysis of variance, while the expression of BCL2 was lower than in the other groups; the difference was statistically significant $(\mathrm{P}<0.05)$. The differences of BCL2 expression in Group B and Group D at $24 \mathrm{~h}$ were not statistically significant by analysis of variance $(\mathrm{P}>0.05)$. 
Group A Group B Group C Group D

\section{$72 \mathrm{~h} \quad 24 \mathrm{~h} \quad 1$ week $72 \mathrm{~h} \quad 24 \mathrm{~h} \quad 1$ week $72 \mathrm{~h} \quad 24 \mathrm{~h} \quad 1$ week $72 \mathrm{~h} \quad 24 \mathrm{~h} \quad 1$ week}

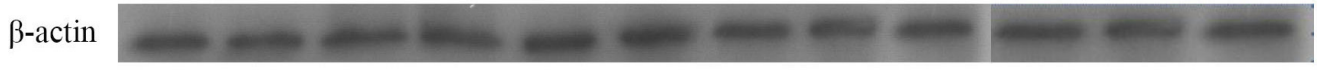

BAX

BCL-2

Figure 6. Expression of BAX and BCL2 proteins in rat spinal cords after ischemia/reperfusion for different times detected by western blot.

Table 2. Western blot to detect the content of BAX and BCL2 proteins in rat spinal cords after ischemia/ reperfusion at different times.

\begin{tabular}{|c|c|c|c|c|c|c|}
\hline & \multicolumn{3}{|c|}{ BAX } & \multicolumn{3}{|c|}{ BCL2 } \\
\hline & $24 \mathrm{~h}$ & $72 \mathrm{~h}$ & 1 week & $24 \mathrm{~h}$ & $72 \mathrm{~h}$ & 1 week \\
\hline Group A & $0.7307 \pm 0.0253$ & $0.6332 \pm 0.033$ & $0.5648 \pm 0.0286$ & $0.6451 \pm 0.0407$ & $0.7157 \pm 0.0151$ & $0.6098 \pm 0.0185$ \\
\hline Group B & $0.6020 \pm 0.0259$ & $0.5614 \pm 0.0381$ & $0.4938 \pm 0.0328$ & $0.7633 \pm 0.0359$ & $0.8193 \pm 0.0108^{*}$ & $0.7354 \pm 0.0636$ \\
\hline Group C & $0.8359 \pm 0.023$ & $0.7895 \pm 0.0202$ & $0.6451 \pm 0.0322$ & $0.5166 \pm 0.0467$ & $0.5958 \pm 0.0166$ & $0.5185 \pm 0.0315$ \\
\hline Group D & $0.4231 \pm 0.0516$ & $0.4231 \pm 0.0516$ & $0.4231 \pm 0.0516$ & $0.8523 \pm 0.0776$ & $0.8523 \pm 0.0776^{*}$ & $0.8523 \pm 0.0776$ \\
\hline
\end{tabular}

*Comparison between two groups $(\mathrm{P}>0.05)$ the rest show comparison between groups $(\mathrm{P}<0.05)$.

\section{DISCUSSION}

The mechanism of SCII involves a complex cascade reaction that may be harmful to the body, the main mechanism including depolarization surrounding the infarction during the acute stage, calcium channel opening, excitatory amino acid toxicity, and free radical release. In the subacute stage, the inflammatory response, oxidative stress, and activation of the apoptosis pathway may ultimately lead to neuronal death (Dirnagl et al., 1999). At present, there is a view that the neuronal death induced by hypoxia and ischemia in nerve cells is mainly due to apoptosis, and is closely related to the regulation of BAX and BCL2 proteins (Hardwick et al., 2012).

The BCL family of proteins are important transit regulatory proteins in the mitochondrial apoptosis signaling pathway. The activation of the BAX protein has a bearing on the activation of the upstream signal of the MEKK and P53 genes, and activates the final pathway of the caspase family of proteins in the downstream apoptosis signal. The membrane permeability of mitochondria is changed by BAX protein activation, and the release of cytochrome $\mathrm{C}$ from mitochondria induces the cascade reaction of the downstream apoptosis pathway. There is still no clear understanding about the initial factors that activate the upstream pathway of the BAX protein, while the activation of BCL2 is through combination of a protein effectorembedded BAX mitochondrial membrane, which prevents the release of mitochondrial cytochrome C, thereby regulating the apoptosis of cells (García-Sáez, 2012).

Low temperature is a double-edged sword; it both protects and damages neural tissue. The mechanism of SCII protection mainly involves reduced metabolism in the ischemic region, inhibition of the release of excitatory amino acids (mainly glutamic acid), relief of 
the inflammatory response, interruption of the apoptosis pathway, inhibition of free radical release, and relief of inflammatory edema (Wu and Grotta, 2013). The damage caused by low temperatures on the central nervous system may be due to the contraction of blood vessels in the spinal cord, higher blood viscosity, slower blood flow, appearance of the "no-reflow phenomenon" in the tiny blood vessels, and aggravation of the ischemia and hypoxia injury (Jia and Pollock, 1997). In our experiments, the Tarlov scores showed that the recovery rate of hind limbs after the occurrence of SCII in the hypothermia group was significantly higher than in the normal control group, while the recovery rate in the hypothermia group was slightly higher than in the deep hypothermia group $(\mathrm{P}<0.05) . H_{\mathrm{E}}$ staining showed that the local tissue swelling and karyopyknosis change in rats of the low-temperature treatment groups after SCII was lighter than in the control group, which was most obvious at $72 \mathrm{~h}$, and the moderate hypothermia protection group was less affected than the deep hypothermia group. The results of Nissl body staining were consistent with the $H_{\mathrm{E}}$ staining results. The changes in the number of Nissl bodies in the hypothermia group were less marked compared with the positive control group, and the injury in the medium and low-temperature groups were less severe than in the deep hypothermia group. The results further verify that low temperatures not only protect the central nervous system, but can also injury it.

The results of TUNEL showed that a large number of TUNEL-positive cells were seen in Group C, followed by Group A, and only a small number of TUNEL-positive cells were found in Group B, while hardly any were found in Group D. Immunohistochemistry and western blot results showed that the expression of BAX protein reached a peak at $24 \mathrm{~h}$ and then decreased gradually, and was highest in Group C, followed by Group A and then by Group B. The expression of BAX protein in Group D was low and stable. The expression of BCL2 protein remained high 1 week after damage, and was highest in Group D, followed by Group B, Group A, and Group C.

In conclusion, this experiment further confirmed that hypothermia has a protective effects on SCII, which may be through regulation of the apoptosis signal pathway to protect the spinal cord tissue. The experiments also revealed that mild hypothermia may have a greater protective effect than deep hypothermia, which can cause vasoconstriction of nerve tissue leading to aggravated ischemia and hypoxia in tissue. In addition, deep hypothermia can promote the expression of BAX to a certain extent, which may inhibit $B c l 2$ gene expression, thereby having a protective effect by reducing apoptosis in neural cells. The experimental results have important significance for SCII protection in clinical vascular surgery. The specific signal transduction pathways involved in the low-temperature regulation of apoptosis and the most effective temperature are topics worthy of further study.

\section{Conflicts of interest}

The authors declare no conflict of interest.

\section{ACKNOWLEDGMENTS}

Research supported by the National Natural Sciences Foundation of China (\#81370230, \#8157021344), the Technology Foundation for Selected Overseas Chinese Scholar, Ministry of Human Resources and Social Security of China (P. Zhu, \#Z012013046), Natural Science Foundation of Guangdong Province, China (\#S2013010014009), and the Science and Technology Program of Guangzhou, China (\#201508020107). 


\section{REFERENCES}

Dirnagl U, Iadecola C and Moskowitz MA (1999). Pathobiology of ischaemic stroke: an integrated view. Trends Neurosci. 22: 391-397.

García-Sáez AJ (2012). The secrets of the Bcl-2 family. Cell Death Differ. 19: 1733-1740.

Güler A, Sahin MA, Ucak A, Onan B, et al. (2010). Protective effects of angiotensin II type-1 receptor blockade with olmesartan on spinal cord ischemia-reperfusion injury: an experimental study on rats. Ann. Vasc. Surg. 24: 801-808.

Guo HM, Zhang JF, Wu RB, Zheng SY, etal. (2004). Abdominal complications after cardiac surgery. Zhongshandaxuexuebao (Med. Sci.) 1: 271-273.

Hardwick JM, Chen YB and Jonas EA (2012). Multipolar functions of BCL-2 proteins link energetics to apoptosis. Trends Cell Biol. 22: 318-328.

Jia J and Pollock M (1997). The pathogenesis of non-freezing cold nerve injury. Observations in the rat. Brain 120: 631-646.

Mahura IS (2003). Cerebral ischemia-hypoxia and biophysical mechanisms of neurodegeneration and neuroprotection effects. Fiziol. Zh. 49: 7-12.

Rivlin AS and Tator CH (1977). Objective clinical assessment of motor function after experimental spinal cord injury in the rat. J. Neurosurg. 47: 577-581.

Wu TC and Grotta JC (2013). Hypothermia for acute ischaemic stroke. Lancet Neurol. 12: 275-284. 